\title{
Understanding the Geography of Post-Traumatic Stress: An Academic Justification for Using a Spatial Video Acquisition System in the Response to Hurricane Katrina
}

\section{Andrew Curtis*, Jacqueline W. Mills*, Barrett Kennedy**, Stewart Fotheringham***, and Timothy McCarthy***}

*Department of Geography, University of Southern California, Karielian Hall (KAP) 416, 3620 South Vermont Ave, Los Angeles, CA 90089-0255, USA.

E-mail: ajcurtis@usc.edu

**College of Art and Design, Louisiana State University, Baton Rouge, LA, USA

***National Centre for Geocomputation, John Hume Building, NUI Maynooth, Maynooth, Co. Kildare, Ireland

In the aftermath of a disaster like Hurricane Katrina, remote-sensing methods are often employed in an effort to assess damage. However, their utility may be limited by the aerial perspective and image resolution. The Spatial Video Acquisition System (SVAS), in conjunction with a Geographic Information System (GIS), has the potential to be a complementary methodology for obtaining damage assessment information as well as capturing recovery related geographies associated with post-traumatic stress. An example is provided from the Lower 9th Ward of New Orleans with data that could be used to predict neighborhood post-traumatic stress. Results reveal six dimensions in which a SVAS can improve existing disaster-related data collection approaches: organization, archiving, transferability, evaluation, objectivity, and feasibility.

\section{Introduction}

$\mathrm{T}$ he use of geospatial support in a disaster, especially geographic information system (GIS) applications, has been discussed for a variety of circumstances (Newsome \& Mitrani, 1993; Pine, 1997; Gunes \& Kovel, 2000; Eichenbaum, 2002; Thomas, Cutter, Hodgson, Gutekunst, \& Jones, 2002; Boyd \& Mills, 2007).
Although the overall response to Hurricane Katrina has generated considerable discussion and critique (Waugh, 2006), geospatial support in the Louisiana Emergency Operations Center (EOC) was widely praised by responders even though it was not staffed by emergency management professionals, but consisted of volunteers drawn largely from Louisiana State University (Curtis, Mills, Blackburn, \& Pine, 2006a,b). 
During the first few days after Katrina made landfall, the Louisiana Governor's Office of Homeland Security and Emergency Preparedness (GOHSEP) relied on an existing relationship with several Louisiana State University (LSU) Centers including the LSU Hurricane Center, CADGIS Research Lab, Southern Regional Climate Center, and Earth Scan Laboratory to provide geospatial support for initial search and rescue activities originating from the state EOC. This support was soon supplemented both in the EOC and in geospatial data production and processing labs across the LSU campus by volunteers drawn from multiple state and federal agencies, the private sector, research centres, and academic departments.

The state EOC was a hub for multiple federal and state agencies, as well as other response teams from across the country. The EOC GIS desk responded to requests with data drawn from existing pre-Katrina sources, remotely processed (e.g., daily flood imagery), and collected by field teams operating through the EOC. One such organization that could have provided timely spatial data to the EOC if a suitable collection system had been used was the American Red Cross (ARC) through their damage assessment process. For most disasters occurring in the United States, the ARC mobilizes a large number of volunteers to the affected region to provide various relief tasks. One of these tasks is the collection of damage assessment data. LSU team members who would eventually be drafted into the EOC became familiar with this data collection process by accompanying ARC teams in the days immediately following the storm. The experiences gained from the EOC, working with $A R C$, and providing support during the recovery to Katrina have given the authors of this article a unique insight into how advances in the collection of geospatial data could be used in future disaster response scenarios, and even during ongoing Katrina recovery operations. This article presents one such advance, the Spatial Video Acquisition System (SVAS), and will demonstrate that if ARC had utilized such a system, geographic aspects of the Katrina recovery operation, and especially the understanding of recovery-related negative health effects at the neighbourhood level, would have been improved. This implied counterfactual argument, which provides justification for SVAS adoption by ARC, is presented as three questions posed for the Lower 9th Ward of New Orleans, each question being linked to a spatial understanding of post-traumatic stress. Furthermore, SVAS is a tool that can not only be used to identify physical landscape features of vulnerable places and post-event resiliency but also as a mechanism for spatially allocating resources to mitigate vulnerability and fortify resiliency. It is from this conceptual framework of vulnerability and resiliency that this case study is set. The two concepts are linked in that resilience is a component of vulnerability as it is the ability to recover. Adger, Hughes, Folke, Carpenter, and Rockström (2005) observe that resilience 'reflects the degree to which a complex adaptive system is capable of selforganization (vs. lack of organization or organization forced by external factors) and the degree to which the system can build capacity for learning and adaptation' (1036). From a practical perspective, Morrow (1999) proposes the development of 'Community Vulnerability Maps' as 'knowledge of where these groups are concentrated within communities and the general nature of their circumstances is an important step towards effective emergency management'. (1) The SVAS can be utilized towards the development of such post-event 'Community Vulnerability Maps' for identifying those attempting recovery, particularly as a tool to serve their mental health needs throughout the recovery process.

\subsection{Data collection by $A R C$ during the response to Katrina}

Damage assessment is a priority of the response phase, and in the United States, as in many other places, remote sensing is a preferred tool for capturing this information. Remote sensing, usually in the form of satellite imagery or aerial photography, is commonly used in the immediate aftermath of a disaster to acquire a visual representation of the 'on-the-ground' situation and to identify sample areas for field-based data acquisition (Yamazaki, 2001). Furthermore, change detection techniques may be used to determine areas of damage. Address-level damage assessment, however, is handled by ARC.

ARC Damage Assessment Teams are comprised of volunteers, usually working in groups of two to four, who drive along all impacted but accessible streets and visually inspect each property via a 'windshield survey'. These data are entered onto a paper form (a 'street sheet') with sections for the street address, the type of residence (single, multiple, apartment), and the degree of damage (Figure 1). Despite these data being geographic, and easily transferable to a GIS environment, the forms usually remain as paper-only records. From working with ARC in the days following Katrina, the question was informally posed to ARC team leaders whether putting these data in a GIS could assist the Disaster Assessment Teams (DATs). Although the potential was recognized, the response was that the existing paper method was the way it had always been done.

This data collection approach is seriously flawed in terms of accuracy, efficiency, transferability to non-ARC uses, and archiving. For example, after Katrina, DATs faced drive times from Baton Rouge to the affected areas that were frequently more than 2 hours in each direction, which limits actual data collection to approxi- 


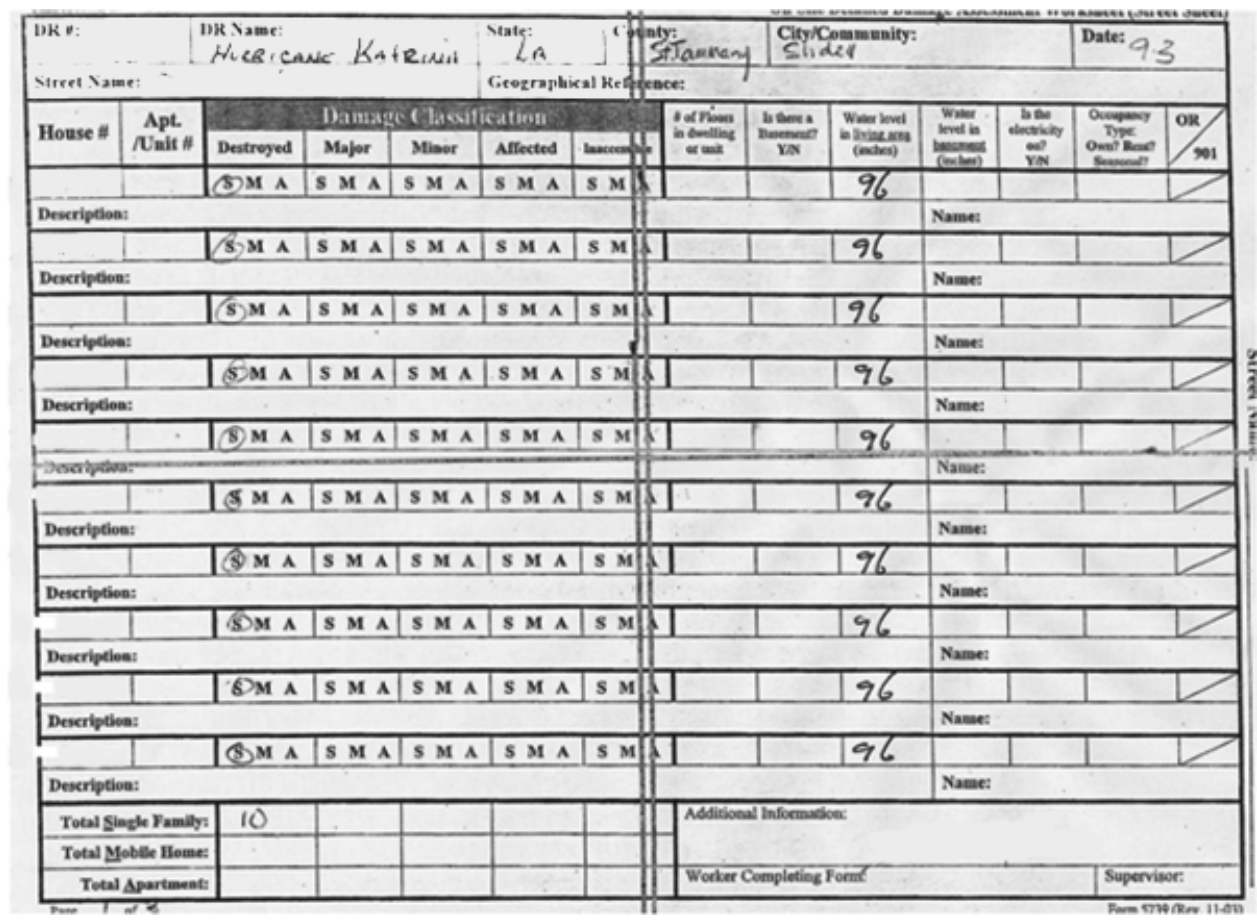

Figure 1. Example of An ARC 'Street Sheet'.

mately 4 hours per day. It should be noted that in nondisaster conditions many of these impacted areas are within 30 minutes to $1 \frac{1}{2}$ hours, but given debris, downed power lines, and a general sense of caution, these trips required additional travel time. Furthermore, due to safety concerns, ARC places limits on when volunteers must return to the base location. Even in the most efficient of ARC operations, this is a limited amount of work given the costs of flying in, housing, and feeding the workers. At its most inefficient, poor route planning, overlapping assessment areas, and gaps in the coverage make this an unacceptable data collection approach. The need for more spatial efficiency is not only important in terms of minimizing ARC costs but also in improving the local community's faith in ARC efforts and in providing useful, timely information to officials in order to improve their situation awareness and decision-making.

With the ARC method, there is also little ability to validate the information once collected. Each team, and each individual on a team bring a degree of subjectivity to the data-recording task (e.g., what does major damage really mean?). In addition, these sheets are filled in with handwritten information that is not always legible. Data that are collected are extremely perishable and have limited transferability, both to other agencies and for future research. If these data were captured electronically, they could be distributed to a variety of responding agencies, even to the EOC itself, in order to gain an additional insight into the spatial extent of the damage. Finally, an electronic version of these data would enable easy archiving that would be useful not only for $A R C$ validation of requests for financial assistance based on residential damage but also to supplement FEMA data on repetitive loss properties, to provide a variety of authorities and residents themselves with a baseline upon which to measure recovery, and of course, for extensive research potential with topics ranging from community vulnerability and resiliency to aspects of structural engineering and disasterresistant construction methods and materials.

LSU researchers working with ARC immediately understood the inefficiency of the existing collection method, and the spatial importance of the collected data. In order to facilitate research and recovery operations, the LSU GIS Clearinghouse Cooperative (LGCC), a Katrina and Rita geoportal whose origin began in the EOC as a means to organize geospatial requests and finished products (Mills, Curtis, Pine, Kennedy, Jones, Ramani, \& Bausch, forthcoming), began the task of transcribing all paper records into a database, a sample of which were then geocoded resulting in a GIS layer and associated attribute table that included address, damage information, and any additional notes transcribed from the 'street sheets'. Damage assessment data such as these could then be aggregated by the predominant damage type in each area (to protect individual house identity) and then combined with Census data (race and income level) to provide a spatial sampling frame for recovery-focused investigations into the resilience of returning communities. This example suggests the greater good that 
could be derived from a standardized GIS-based ARC dataset. The SVAS provides such a data collection approach that is less expensive, more accurate, can be standardized, and produces easily transferable (and easily archived) GIS data. Furthermore, its application towards improved understanding of resiliency measurements and allocation of services based on these metrics offers real potential for providing effective support to communities in a post-disaster environment.

\section{A Research and Recovery Justification: The Geography of Stress}

Given the perishable nature of disaster event-based data and its untapped potential for providing an insight into the current disaster and future events, it is impractical to allow critical, irreplaceable data to perish. Although valuable in the response, in a prolonged recovery period these data could be used to understand the spatially disproportionate effects of the disaster and target resources to facilitate neighbourhood rebuilding. In keeping with this last point, SVAS data collected for the Lower 9th Ward in April 2006, data collected in the same manner as by deployed ARC DAT, are used to answer three questions associated with post-traumatic stress, a health outcome that continues to disproportionately affect vulnerable populations after Katrina (Curtis, Mills, \& Leitner, 2007).

Katrina generated stress on multiple levels for those directly impacted by the storm (Bourque, Siegel, Kano, \& Wood, 2006; Madrid, Grant, Reilly, \& Redlener, 2006). This stress results from a variety of situations: being stranded, feeling abandoned, being 'rescued' to a shelter such as the Superdome, and being relocated multiple times from places of refuge. Additional stress factors could include not hearing from loved ones, losing family and neighbourhood support structures, losing contact with caregivers, not having access to medication, and accentuating chronic illnesses (Cefalu, Smith, Blonde, \& Fonseca, 2006). These 'stresses' can also be categorized geographically according to their source, including: the geography of experiencing the storm, evacuation and relocation stress, pre-Katrina stress and associated health outcomes, and rebound and recovery potential (Curtis et al., 2007). Presenting this stress surface even more simplistically, the likelihood of individuals from a neighbourhood experiencing post-traumatic stress is as a result of $A_{1}+B+A_{2}$, where $A_{1}$ represents pre-disaster vulnerability, $B$ represents the experience of the disaster, and $A_{2}$ represents implications for post-disaster problems based on pre-disaster vulnerability. Although $A_{1}$ and $A_{2}$ have similar origins, these vulnerabilities are linked to the severity of the disaster experience itself, and the ability to rebound from that experience.

For example, traditionally vulnerable populations, especially those living in poor and minority neighbourhoods, are more likely to experience rescue, evacuation, and relocation. They are also likely to already carry chronic illness such as hypertension or diabetes (Cefalu et al., 2006), and have a predisposition to mental health problems due to their pre-disaster neighbourhood living environments (e.g., high crime rates causing anxiety) (Madrid et al., 2006). In addition, they may not have the financial, political, or even educational ability to rebound and begin the recovery of their homes, neighbourhoods, and lives. Therefore, even if a disaster physically impacts all groups in society equally, the effect of the disaster may still be felt disproportionately in the recovery period. This disproportionate impact is complex, but can be built from different geographic layers representing factors from $A_{1}, B$, and $A_{2}$.

Data for this surface could be extracted from the US Census (where most measures of traditional vulnerability can be found and extracted), or from layers created at the time of the disaster such as high-resolution imagery (to assess the degree of damage). Examples of data type could include the ability to be able to evacuate $\left(A_{1}\right)$, the experience of the storm and risk of life (B), and the potential for community rebuilding $\left(A_{2}\right)$. One factor that can reduce the impact of post-traumatic stress is the return to normalcy, a large part of which is the physical return of the local community. Indeed, residents from economically deprived and especially minority neighbourhoods in urban Louisiana are traditionally reliant on their community for support, with strong family and neighbourto-neighbour ties (Curtis \& Leitner, 2005). For example, there is a high proportion of single African American mothers in New Orleans, with childcare support often coming from community-proximate (female) relatives, or neighbours. The strength of this community support is so strong that it can in itself be an impediment to evacuation from a disaster. Simply put, there is a need to re-establish the community by rebuilding and returning residents as quickly as possible. Two spatial data inputs for gauging this return would be the degree of devastation and the incremental repopulation of the neighbourhood.

Understanding the spatial surface of stress is necessary in order to serve vulnerable populations, and assist in building resiliency. This group of people often sustain undiagnosed mental health problems (Rehner, Kolbo, Trump, Smith, \& Reid, 2000); therefore, an understanding of the prospective mental health problems by neighbourhood could effectively target those communities most in need. Without such an intervention, the disproportionate impact of Katrina could be seriously prolonged. Many New Orleans neighbourhoods, including the Lower 9th Ward, were already vulnerable to $A_{1}$ risks associated with income and race. Fothergill and 
Peek (2004) note that, for the poor, the psychological impact of disaster varies by the stages of the event and that overall they are more prone to experiencing psychological stress, and yet are less likely to have the resources to assist in these issues (95-96). Furthermore, the relocation has its own psychological implications (Garrison, 1985), while experiencing the event also brings its own difficulties. Hence, understanding the geography of those who experienced the storm as well as of those who relocated (and many who have done both) is critical to understanding the geography of stress in post-Katrina New Orleans (Curtis et al., 2007). Indeed, the population from the Lower 9th Ward may be used to encapsulate the spectrum of social troubles of New Orleans. This area also gained national prominence because of the severe flooding associated with breaks in the Industrial Canal. For these reasons, this neighbourhood is used to illustrate how ARC-employed SVAS information, collected temporally close to Katrina's landfall, could be used for months and even years later to support the community rebuilding process. Three questions are asked, each being an example taken from the three input categories $\left(A_{1}, B\right.$, and $A_{2}$ ) used in the calculation of a Geography of Stress surface.

What evidence exists that the residents of the Lower 9th Ward remained behind when Katrina made landfall? Residents may have remained behind because they either (a) did not have the ability to leave (no transportation), (b) had transportation but did not have the ability to use that transportation (no money for gas or a motel stay), or (c) chose to remain behind due to a variety of factors, including (but not limited to) not fully appreciating the severity of the situation, or having especially strong ties to the immediate community and the security net it provided. The variable extracted from the SVAS to represent those who remained behind, a proxy for ' $A_{1}$ ' vulnerability, is the number of abandoned cars, which are identified by the presence of a floodwater mark on the vehicle.

Was the level of flooding in the Lower 9th Ward high enough to be life threatening? Katrina generated stress on multiple levels for those directly impacted by the storm (Bourque et al., 2006; Madrid et al., 2006). Post-traumatic stress has several contributing factors that can accentuate and lengthen its debilitating effect. Arguably, the most important factor is the experience itself. If a resident from the Lower 9th Ward remained behind, was he/she in danger of losing his/her life to the floodwaters? To measure the answer to this question, the SVAS is used to extract flood heights on the buildings. Obviously, the Lower 9th Ward was not flooded during the video capture, but similar SVAS units could have been attached to rescue boats. If the video survey had been completed soon after the floodwaters had receded, flood height marks would have been more obvious and therefore flood depth estimates could have been more quickly and accurately recorded. However, even in April 2006, high water marks were still visible on houses, cars, and fences and therefore provide evidence of the potential spatiality of those who experienced the storm's physical impact, an indicator of ' $B$ ' stress in the above calculation.

How many buildings in the surveyed area of the Lower 9th Ward appeared to be structurally sound? One of the best coping mechanisms to stave off post-traumatic stress is to 'take control', to plan and begin acting on a strategy to return home. Not only is the condition of the physical residential structure important, so too is the idea of returning home as a member of a known and familiar community. Therefore, in summary, the population most vulnerable to the events of Katrina, the population most likely to still be displaced, is the population having the greatest need to return. By capturing building fecundity, an estimate of neighbourhood return potential is possible; therefore, it is extracted from the SVAS as a proxy of the ' $A_{2}$ ' input.

\section{A Spatial Video Acquisition System}

The National Center for Geocomputation (NCG), at the National University of Ireland, Maynooth, has developed a software browser that allows for both GIS layers and video to be synchronized and viewed simultaneously. Similar systems are occasionally used by state transportation agencies in the United States utilizing a vehicle equipped with digital video cameras synchronized to a GPS unit, for example the Oregon Department of Transportation's online 'Digital Video Log' (DVL) where users can choose to view video on a variety of Oregon roads (ODOT, 2007). These cameras graphically record the condition of the road surface, as well as the roadside infrastructure, ranging from buildings to road signs. These data can be uploaded to a GIS, or viewed in a customized browser, allowing the user to observe both video and geographic location simultaneously.

The SVAS used for the collection of data from the Lower 9th Ward comprised a digital camcorder, a GPS encoder, camcorder mount, and power unit. GPS information was encoded onto one of the two (stereo) audio tracks of the digital video recording. The digital camcorder was attached to the right-hand side of the car by a window mount (Figure 2). The car was driven at approximately 10-15 miles per hour through the Lower 9th Ward in the vicinity of the Industrial Canal levee failure. The video was processed using a GPS decoder and an industry standard frame capture card and the GPS timing and navigation information were extracted as the video frames were captured. 


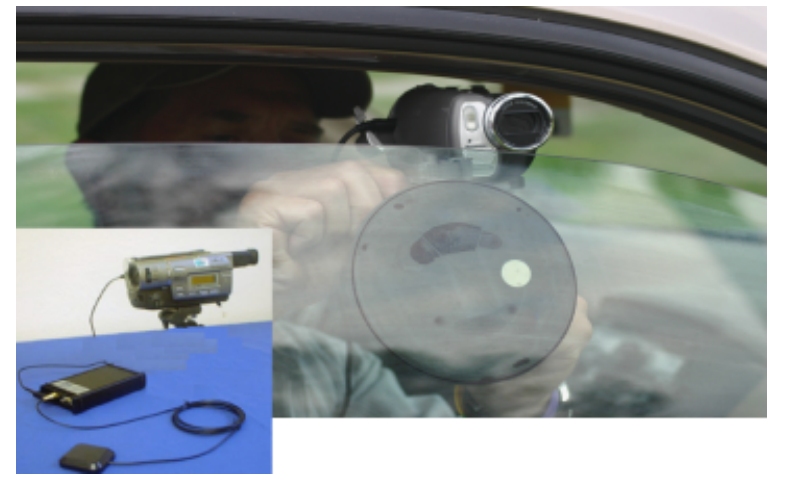

Figure 2. Configuration of Spatial Video Acquisition System.

Spatially indexed video or imagery is a term reserved for multiple geocoded images recording some phenomenon. This close-range remote-sensing tool differs from conventional recording methods in that a continuous data stream of spatially indexed images are used to record the feature rather than one large image map. Because images are small, typically $<1,000 \times 1,000$ pixels, large quantities of images can be captured and integrated into the data set, and consequently this method is well suited for collecting data along route corridors. In the SVAS configuration, the field of view (FOV) is rotated $90^{\circ}$ and is therefore different from the usual plan view of conventional mapping systems. These systems can be calibrated and result in a rich geographic data source where information can be extracted and presented to the user in a more intuitive manner. Integrating this human-scale, image-mapping tool with other sensors results in a system that can be easily deployed and used to produce useful information for emergency managers whose responsibilities demand solutions that facilitate a rapid response.

Video frames were processed and tagged with GPS coordinates, date, and time before being saved to a hard disk. AGIS layer was created in which each record pointed to a unique video frame. Metadata tables were automatically constructed and a browser allowed the user to choose any particular survey using a pull-down menu. The resulting browser allowed a user to follow the path of the vehicle on a GIS-style interface, with one window showing the path of the vehicle overlaid on other GIS layers such as building plats while the actual video ran in the other window (Figure 3). A second camera could have been added to capture the left side of the road, thus doubling data collection speed. The system also produced a GIS dataset containing a coordinate location linked to the library of 14,746 still images that comprised the 1-hour-long video-captured record. For the purpose of this article, information was extracted from each image (including vehicle locations, flood heights, and building fecundity) and added as attributes to the GIS coordinate file. This was achieved by linking a captured frame containing the relevant attribute to its associated coordinate. Coordinates and attributes were combined in Arc 9.1 and overlaid on other Lower 9th Ward layers, such as high-resolution aerial photography of the damaged city, and FEMA's flood depth grid.

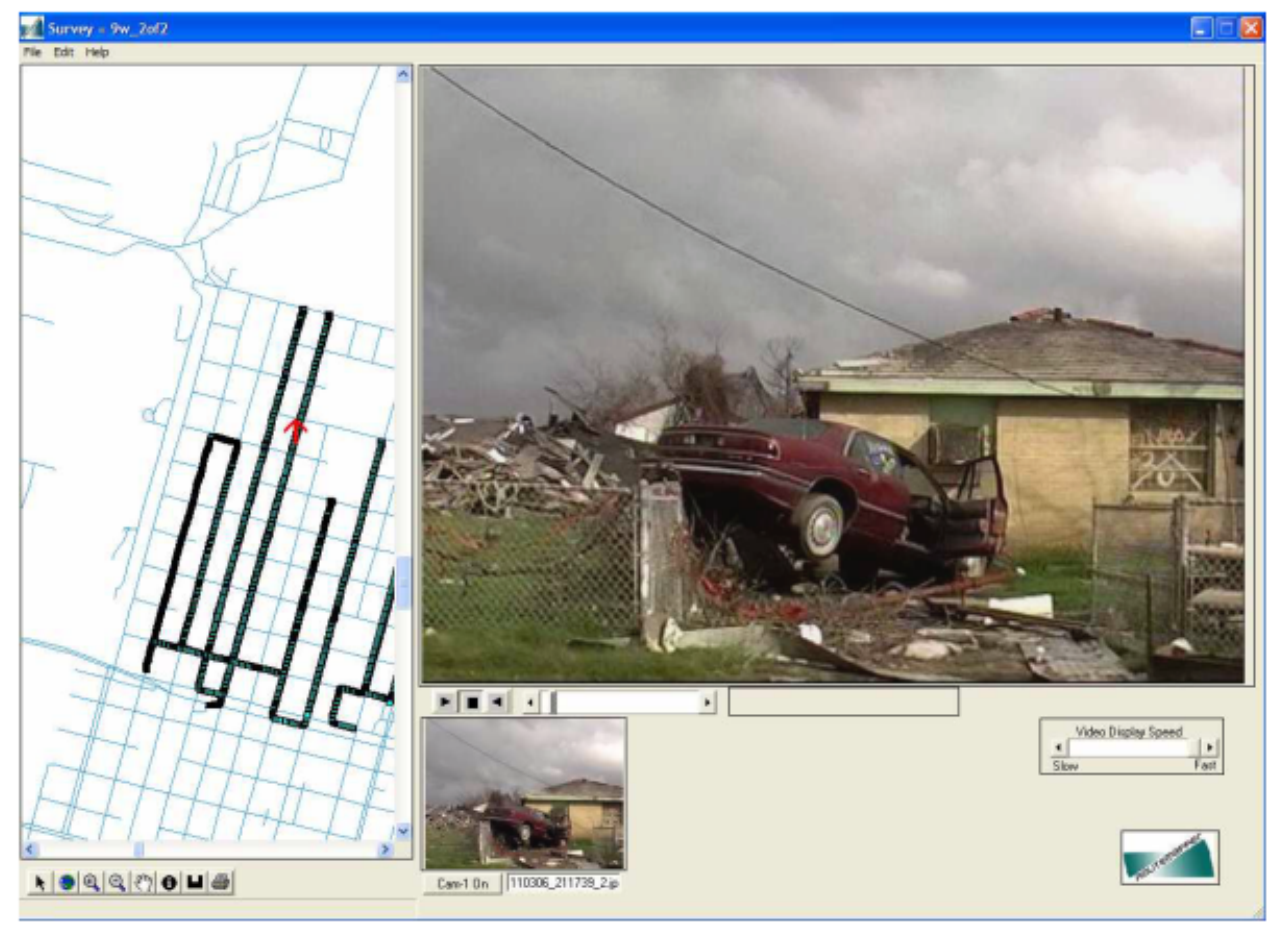

Figure 3. Browser Depicting Map Display on the Left and Video on the Right. 


\section{Results}

\subsection{Abandoned vehicles as markers of those who remained behind}

The location and number of abandoned vehicles were extracted from the SVAS and displayed in Arc 9.1. These are displayed in Figure 4 as proportional circles occurring along the data collection route. Within this approximately 1 square mile area of the city, there were 404 abandoned vehicles, and approximately 3,000 buildings. It is impossible to identify how many of these vehicles were serviceable before the hurricane, although a sizeable number appeared as possibly drivable, for example sitting in the driveway of the house. The speed of water entering the Lower 9th Ward from the Industrial Canal meant that it would be impossible to attempt to flee by driving. Therefore, as long as the family did not have a second car, or as long as they did not use an alternative method of evacuation even though they owned a car, the presence of a serviceable car is a potential proxy indication of a family remaining behind and therefore experiencing the flooding. All neighbourhoods in post-hurricane New Orleans contained these 'Katrina cars', and an accurate count of these could also help to better inform future evacuation strategies for the city. As with the other two questions,

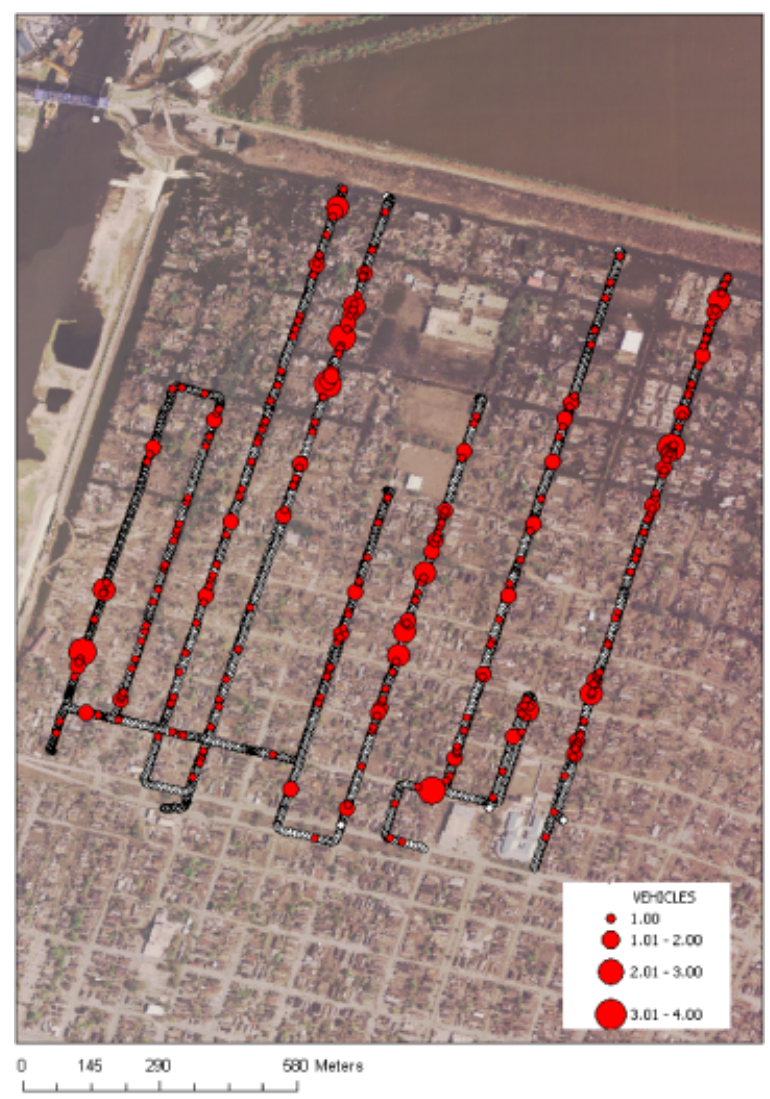

Figure 4. Locations of Abandoned Vehicles in the Lower 9th Ward. this result is more of an illustration of what could have been achieved in post-Katrina neighbourhoods had SVAS technology been used by organizations such as ARC. However, the number of cars in proportion to the number of residences strongly suggest that many residents remained behind and experienced the flooding.

\subsection{Was the level of flooding in the lower 9th ward high enough to be life threatening?}

Figure 5 displays the path taken with the SVAS overlaid on a flood depth grid developed by FEMA and the Army Corps of Engineers. The depth grid is based on satellite imagery (created on the 2 September 2005) supplemented by field teams of engineers who visited properties and measured flood heights as evidenced by high water marks.

Each building captured on the SVAS was examined for evidence of a flood height, the most telltale marking being a series of dark lines showing where the floodwater settled. These lines were more easily seen on a light-coloured house. Houses where these flood marks were visible are shown in Figure 5. As a further indicator of post-canal break activity, Figure 5 also shows the location of 26 boats that were left after the floodwaters receded. From approximately 3,000 buildings, only 14 houses displayed identifiable flood markings. When these 14 houses were overlaid on the FEMA depth grid, 11 were within $1 \mathrm{ft}$ of the grid depth for that location (six were at a higher elevation according to the SVAS). The method of height estimation was based on standard building features, such as doorframes, and concrete steps for raised buildings. The largest discrepancy between the wall mark and the depth grid was slightly in excess of $2 \mathrm{ft}$. Three houses displayed flood marks of $7 \mathrm{ft}$, three with $6 \mathrm{ft}$, four with $5 \mathrm{ft}$, three with $4 \mathrm{ft}$, and the lowest at $3 \frac{1}{2} \mathrm{ft}$. The depth grid displayed even greater flood heights, some areas of the Lower 9th Ward exceeding $15 \mathrm{ft}$. It is worth remembering that the flood settle line is lower than the initial surge of water. Even from these limited data, it is possible to conclude that flood heights within this neighbourhood were high enough to be life threatening.

\subsection{How many buildings in the surveyed area of the lower 9th ward appeared to be structurally sound?}

By referring to each captured frame on the SVAS video, 272 buildings (out of the approximately 3,000 within the survey area) were identified as having survived with a reasonable degree of structural integrity. Structural integrity, as was defined for the purpose of this project, presents the residence remaining on its foundation 


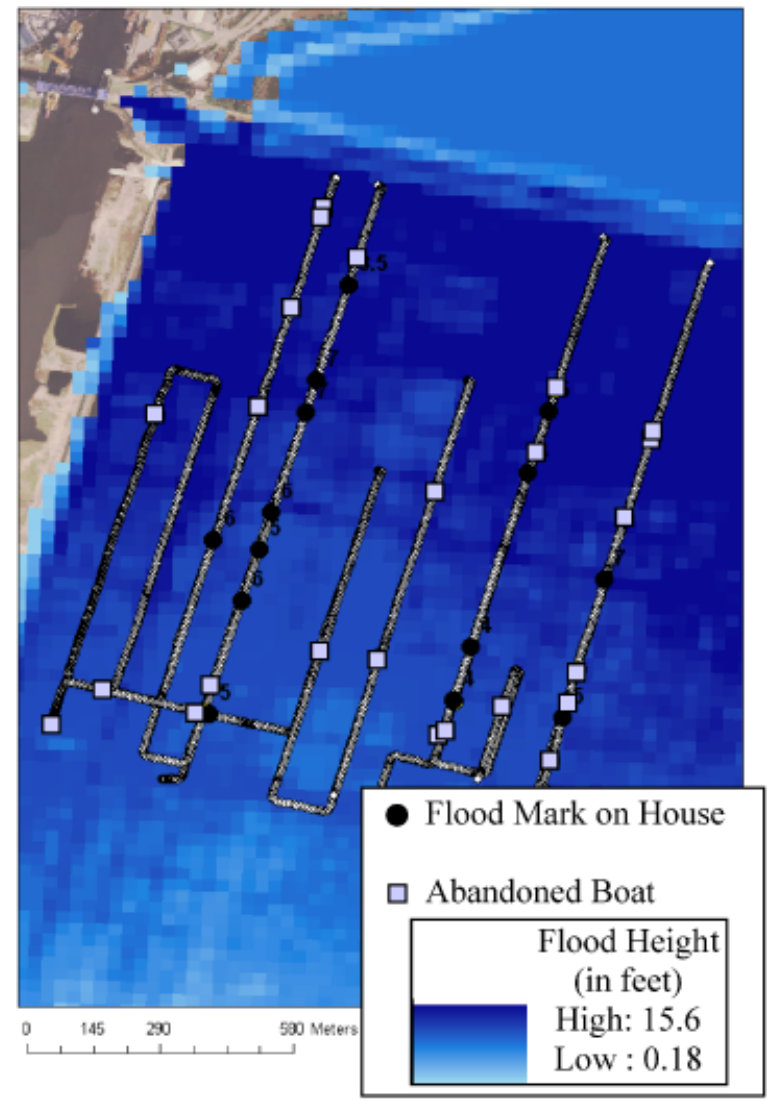

Figure 5. Flood Height Estimates Taken from Watermarks on Buildings, and Locations of Abandoned Boats.

and not having suffered any evidence of wall collapse. Obviously, all structures suffered some degree of flooding.

The northern break of the Industrial Canal can be seen in the top left corner of Figure 6. Buildings are identified along the SVAS path where little structural damage was sustained. The inset map displays a detail of four such buildings, these being surrounded by considerable destruction. From Figure 6, it is possible to identify areas along the path that sustained complete damage, while in other sections the majority of buildings retain fecundity. By comparing the results of a 'faceon' inspection made possible by viewing the SVAS with a birds-eye inspection of high-resolution aerial photography flown in the week following Katrina, an additional seven of the 272 houses were identified as being displaced from their original support. Further, one house had suffered structural damage in the rear not visible from the road. Given the ARC requirement that DATs stay in their vehicles while conducting surveys and given the SVAS limitation of only capturing front and some side views, these 'mistakes' would also have been made using either method. The remaining houses appeared salvageable from both a face-on and birds-eye perspective. Therefore, the Lower 9th Ward sustained major damage as widely reported in the media,

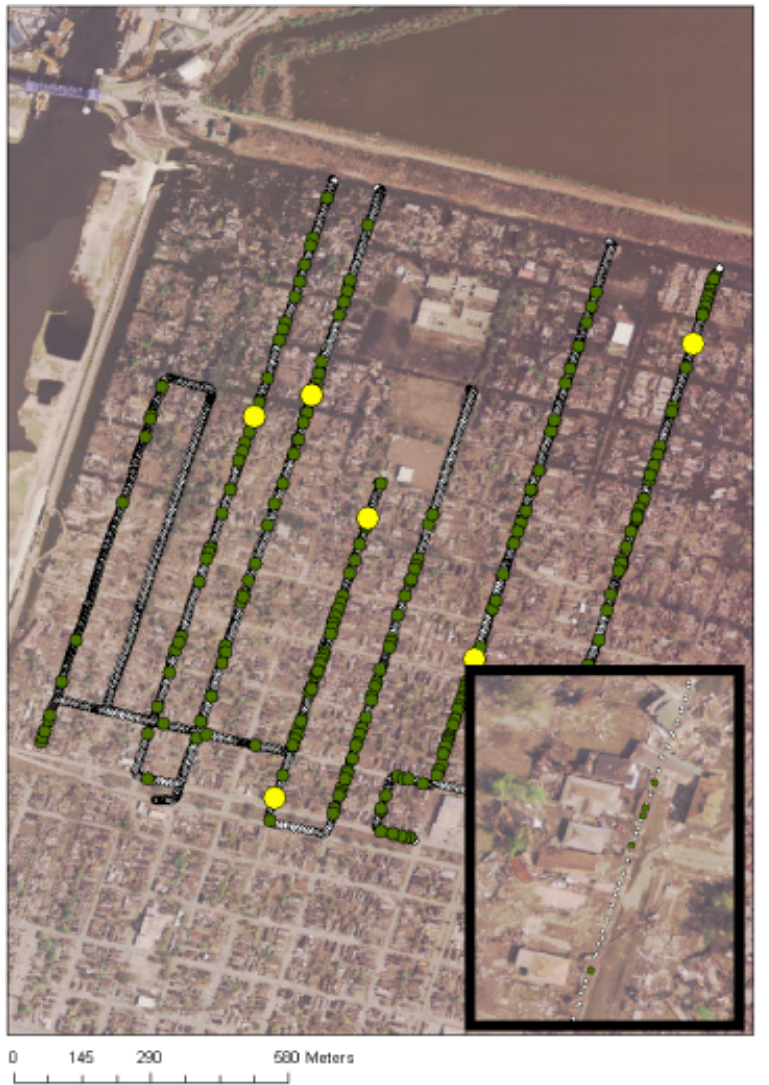

Figure 6. Locations of Houses Displaying Fecundity on the Spatial Video Acquisition System.

although numerous buildings, and in some cases sizeable street sections display enough fecundity to allow rebuilding (Figure 6).

\subsection{Comparing ARC DAT with SVAS}

In addition to overall improvement in existing tasks, the dataset(s) resulting from SVAS hold extensive, yet untapped, potential for multiple uses. In consideration of the quality of data layers that can be generated from each method, the ARC method is limited, whereas the SVAS method is considerably less restrictive with its ability to capture, and thus create spatial layers based upon the entirety of the street-level visual perspective as well as providing greater certainty about layers due to the availability of source data (video), which allows revisiting a place (both in video and in the field for longitudinal comparison), as well as being suited for archiving and replication (Table 1).

By comparing the ARC DAT method with the SVAS method, the SVAS emerges as offering six dimensions of improvement over the ARC method: organization, archiving, transferability, evaluation, objectivity, and feasibility (Table 2). 
Table 1. Comparison of Resulting Dataset(s) from Spatial Video Acquisition System (SVAS) and American Red Cross (ARC) Methods

\begin{tabular}{ll}
\hline SVAS & ARC \\
\hline Certainty & Uncertainty \\
Objectivity & Subjectivity \\
Archived & Perishability \\
Data limited to & Data limited to \\
all visual capture & street sheet \\
Replicable & Not replicable \\
\hline
\end{tabular}

From the organizational dimension, users could manage route coverage, therefore eliminating duplication while confirming that all areas have been captured (i.e., for decision support about which areas have been assessed). The archiving and transferability dimensions provided by SVAS are a step towards addressing Alexander's (2000) assertion that 'The practical and academic study of disasters is inhibited by the incompleteness and unreliability of basic statistical data' (36). SVAS can provide such a data collection method with the advantage of allowing the return to the original source data by secondary investigators for future validation and critiquing. This 'revisiting' of these data can also be used to answer future research questions not originally identified at the time of collection. The SVAS also provides a dimension of evaluation (i.e., where are people visibly working on homes) that is especially useful if data are collected systematically through time, with the original data run providing a baseline for recovery. SVAS, then, is one method of creating a spatially comprehensive event-based resource that can be shared with others for a variety of purposes. It is comprehensive in that it can be used to capture all areas of damage (even being loaded onto watercraft) and it is easily sharable/transferable due to the common image file format. Furthermore, SVAS is a step towards a 'greener' recovery process, given the savings on vehicles and fuel, while also providing more opportunity for developing objectivity (fewer eyes and trained eyes); data analysts can be trained for specific data extraction activities, therefore adding a dimension of objectivity to the existing ARC method. Finally, the SVAS brings a dimension of feasibility, as this method requires fewer workers and vehicles accompanied by less fuel, food, and water.

In addition, this method has untapped 'value-added' when analysed in concert with satellite imagery or aerial photography. For example, by using SVAS flood depth can be ascertained from flood marks (high water marks) on structures; building fecundity can be seen in part by a structure being on or off its foundation; return and recovery can be captured by identifying portable toilets erected at street corners, or the status of lawn care (e.g. overgrown yards), while environmental health issues can be captured through visible mould growth.
Table 2. Spatial Video Acquisition System Dimensions of Improvement

\begin{tabular}{ll}
\hline Dimension & Description \\
\hline $\begin{array}{l}\text { Organizational } \\
\text { Archival }\end{array}$ & $\begin{array}{l}\text { Manage route coverage, allocate resources } \\
\text { Longitudinal for comparison, capture for } \\
\text { 'lessons learned' } \\
\text { To multiple organizations and public, to } \\
\text { other events } \\
\text { Evansferable }\end{array}$ \\
Objectivity & $\begin{array}{l}\text { In-lab classification with fewer people, } \\
\text { trained people }\end{array}$ \\
Feasibility & $\begin{array}{l}\text { Fewer people, fewer vehicle rentals, less } \\
\text { fuel, paperless }\end{array}$ \\
\hline
\end{tabular}

Returning to the focus of this paper, mental health services can be allocated to returnees in need, for example by identifying pioneer returnees (residents rebuilding with no one else around) who may need support in the absence of community.

\section{Conclusion}

A post-Katrina survey conducted in a Texas shelter found that the majority of refugees $(61 \%)$ did not heed the original evacuation order, with $36 \%$ listing the reason as a lack of means to evacuate (Bourque et al., 2006). The 2000 Census put the number of residents from New Orleans as not having access to transport at approximately 250,000 (Bourque et al., 2006). Census Block information for the section of the Lower 9th Ward covered by the SVAS lists $30 \%$ of occupied housing units not owning a vehicle. However, to believe that all residents did not evacuate because of a lack of transportation options is far too simplistic. From the same shelter survey, $29 \%$ listed the reason as not evacuating as being because they underestimated the storm (Bourque et al., 2006). Other reasons for not evacuating could have included not wanting to abandon pets, not having the financial resources to leave (both gas and motel costs), and having nowhere to go (Dow \& Cutter, 1998; Dow \& Cutter, 2000; Dow \& Cutter, 2002; Bourque et al., 2006). In addition, those in poverty are often reliant on their community environment, with the fear of being removed from that support structure being overwhelming and a serious deterrent to leaving. Understanding where and then why people did not evacuate from Katrina is one example of a research topic that could have been approached using SVAS data if the technology had been used comprehensively across Katrina-impacted areas.

The number of cars left in the flood is not a perfect indicator of those persons or families who remained as some families did not own cars (although these people 
also probably remained) while some were multiple-carowning families (again these being a limited subset for this generally poor area of New Orleans). However, in the absence of interview data, a car count in combination with census information for each block group (number of families without cars, and multi-car owning families) can be used to approximate the number who remained behind and experienced the storm and subsequently as a spatial predictor of these behaviours in advance of future disaster events. Although personal interviews are likely the best determinant of how Katrina was experienced, the SVAS survey, if it had been conducted for the entire city, could have provided a neighbourhood-by-neighbourhood experience index, which in turn could have been used to geographically target resources to monitor post-traumatic stress.

The second variable extracted from the SVAS, which should also be used in combination with the previous car count data, is the severity of the disaster, in this case represented by flood height. The relatively few houses that could be used to gauge flood height was due to the number of severely damaged properties, and the length of time between Katrina and the collection of SVAS data. Even so, it was evident that flooding was high enough to pose a serious risk to life. If the SVAS had been used while the area was still under water, the elevation measurement of the GPS would have provided a more accurate reading. If SVAS data had been collected immediately after the water drained away, watermarks on buildings would have been more clearly discernible. The combination of the presence of cars and flood height can be used as a proxy to an aggregate 'experience' for this area of New Orleans, and again serve as an input into a geographic prediction of posttraumatic stress.

A further benefit of collecting SVAS data is that flood prediction and damage models, such as HAZUS, could be recalibrated to achieve a higher accuracy. It should be remembered that the depth grid against which the watermark heights are compared is largely an interpolated surface built from sources that would have benefited from the addition of SVAS data.

Finally, the SVAS data were used to determine the return potential for the Lower 9th Ward. The majority of the destruction occurred as a result of two levee breaks on the Industrial Canal. Houses proximate to these breaks were completely destroyed, most being washed from their piers or concrete slab foundations. As a consequence, a common perception is that the entire Lower 9th Ward must be razed. However, it was evident from the SVAS data that a number of properties retained fecundity and could be rebuilt. This is important for a population so tied to the sense of neighbourhood, especially as many sections and not just single houses (and therefore partial communities) were salvageable. This is particularly important when consider- ing that an ameliorating factor of post-traumatic stress in those who stayed behind and experienced the storm is the return to normalcy and community.

For the purpose of the questions posed in this article, data captured from the SVAS on building damage or fecundity, indeed data supposedly captured on traditional ARC street sheets could be used as a gauge as to how quickly communities could be rebuilt and the residents returned. These data could be supplemented with other information extracted from the SVAS, such as building construction type, degree of surrounding damage (indicating the likelihood of neighbours returning to their property), and whether the property was of cultural or historical value, an important consideration in New Orleans.

The important point to be taken from this article is that the answers to these three questions posed here are factors related to post-Katrina community resiliency, especially when considering post-traumatic stress. These could have been extracted from GIScompatible data collected by ARC as part of their normal damage assessment process. If ARC had used SVAS, data collection would have been quicker, more accurate (with the possibility of validation), and immediately transferable to other units, for example the EOC. More importantly, these data can be used in ways to not only immediately inform those who were displaced but also aid in unforeseen activities associated with the recovery. From an academic standpoint, if ARC had collected these data using an SVAS, the realm of post-disaster research would have been dramatically expanded.

\section{Discussion}

Unfortunately, 17 months after landfall, many neighbourhoods in New Orleans and in the surrounding parishes remain either deserted or with limited residential return. The theory of interdependency places the actions of the individual in the context of the actions of the whole, which in this case can be defined as the neighbourhood (Kunreuther, 2006). Therefore, a question facing potential returnees, presuming they have the financial ability, is why rebuild if the immediate neighbourhood, or even a portion of a neighbourhood block, are not rebuilding? To what degree can mould toxicity found in a neighbour's abandoned residence affect those who are rebuilding next door? Will the rebuilding effort (and cost) be futile if the neighbourhood has to be bulldozed anyway? In December 2007, on a trip into St. Bernard Parish, adjacent to the Lower 9th Ward in New Orleans, three types of signs were often visible on the same property: 'house for sale', 'do not bulldoze', and mandatory bulldoze notices or 'red tags'. These conflicting messages illustrate the uncer- 
tainty surrounding whether a neighbourhood will be rebuilt. This uncertainty is faced by both the displaced needing information about his/her community, and by those who have returned and are trying to rebuild among the devastation.

The tardy return to Katrina-impacted neighbourhoods is not just an emotional debating point; it also has implications for the continued disproportionate impact of the catastrophe on vulnerable populations. This article has shown how SVAS could have been used to judge return potential at the neighbourhood level. However, the same technology can also be used as an active component of the return process. If the same route were driven on a regular basis, this rate of return can be monitored and might provide an incentive for other displaced people to return or to give them the evidence they need to decide not to return. Lack of information or discrepancies in information have made this decision difficult and uncertain for many displaced people. Through SVAS and an effective protocol for dissemination of this information, people would be empowered to make a more informed decision about their future. For even on this single run, a gauge of the level of community resilience and desire to return by residents can be seen as the larger dots in Figure 6, which indicate those properties where residents had placed a sign declaring their wish for the property not to be demolished. Other signs of return, which could be extracted from the SVAS, include evidence of building work (e.g., mini-bulldozers), building protection (the blue tarp 'FEMA Roof'), and even images of residents working on their property.

For those still displaced, there is a need for freely available and easily interpretable information about the state of the neighbourhood. Community measures such as neighbourhood toxicity levels, school openings, service provision, and even food stamp transactions can all provide an insight; with SVAS, this insight is communicated in its most powerful form, by location with images. It is possible that with the regular use of an SVAS, with results being presented on a website that can be updated at regular intervals, displaced residents will be able to virtually visit their neighbourhood block, witness the revitalization of their community, gauge the risks of their own timetable to return, and finally, formulate a better-informed plan of action for themselves and their family. If this display was linked to other environmental investigations, and the status of local area services, it would help alleviate some of the uncertainty associated with the decision to return. The SVAS would be a valuable tool to democratize information to those who are most vulnerable, who may not be able to afford to return to the city on a regular basis, and who may not have the educational background to interpret official statistics or read and comprehend lengthy governmental reports. As academics, the geospatial capture and archiving of these rebuilding efforts may provide insights into what can be expected in the recovery process in future catastrophes. Furthermore, what we learn from the data gathered by this technology has the potential to alter or improve and, thus, inform the recovery process in future events.

\section{References}

Adger, W.N., Hughes, T.P., Folke, C., Carpenter, S.R. and Rockström J. (2005), 'Social-Ecological Resilience to Coastal Disasters', Science, Volume 309, pp. 1036-1039.

Alexander, D. (2000), Confronting Catastrophe, Oxford University Press, Oxford.

Bourque, L.B., Siegel, J.M., Kano, M. and Wood, M. (2006), 'Weathering the Storm: The Impact of Hurricanes on Physical and Mental Health', Annals of the American Academy, Volume 604, pp. 129-151.

Boyd, K.A. and Mills, J.W. (2007), 'GIS Applications During Response to Hurricane Katrina: Small, Local Government and State Government Experiences, Directions Magazine. http://www.directionsmag.com/article.php? article_id = 2466 \&trv $=1$ (accessed 25 June 2007).

Cefalu, W.T., Smith, S.R., Blonde, L. and Fonseca, V. (2006), 'The Hurricane Katrina Aftermath and its Impact on Diabetes Care: Observations from 'Ground Zero': Lessons in Disaster Preparedness of People with Diabetes', Diabetes Care, Volume 29, pp. 158-160.

Curtis, A. and Leitner, M. (2005), Geographical Information Systems and Public Health: Eliminating Perinatal Disparity, Hershey, GP/INFOSCI/IRM Press Hershey.

Curtis, A., Mills, J.W. and Leitner, M. (2007), 'Katrina and Vulnerability: The Geography of Stress', Journal of Health Care for the Poor and Underserved, Volume 18, pp. 315-330.

Curtis, A., Mills, J.W., Blackburn, J.K. and Pine, J.C. (2006a), 'Hurricane Katrina: GIS Response for a Major Metropolitan Area, Quick Response Research Report 180 Natural Hazards Center, University of Colorado. http://www.color ado.edu/hazards/research/qr/qr180/qr180.html (accessed 25 June 2007).

Curtis, A., Mills, J.W., Blackburn, J.K. and Pine, J.C. (2006b), 'University and Government Collaboration in Hurricane Katrina: Geospatial Decision Support in the EOC', International Journal Mass Emergencies and Disasters, Volume 24, Pp. 203-221.

Dow, K. and Cutter, S.L. (1998), 'Crying Wolf: Repeat Evacuation Issues: Repeat Response to Hurricane Evacuation Orders', Coastal Management, Volume 26, pp. 238-252.

Dow, K. and Cutter, S.L. (2000), 'Public Orders and Personal Opinions: Household Strategies for Hurricane Risk Assessment', Environmental Hazards, Volume 2, pp. 143-155.

Dow, K. and Cutter, S.L. (2002), 'Emerging Hurricane Evacuation Issues: Hurricane Floyd and South Carolina', Natural Hazards Review, Volume 1, Pp. 12-18.

Eichenbaum, J. (2002), 'CAMA, GIS, and the Recovery of New York City', Assessment Journal, Volume 9, pp. 17-22.

Fothergill, A. and Peek, L.A. (2004), 'Poverty and Disasters in the United States: A Review of Recent Sociological Findings', Natural Hazards, Volume 32, pp. 89-110. 
Garrison, J.L. (1985), 'Mental Health Implications of Disaster Relocation in the United States: A Review of the Literature', International Journal of Mass Emergencies and Disasters, Volume 3, pp. 49-65.

Gunes, A.E. and Kovel, J.P. (2000), 'Using GIS in Emergency Planning Operations', Journal of Urban Planning and Development, Volume 126, pp. 136-149.

Kunreuther, H. (2006), 'Disaster Mitigation and Insurance: Learning from Katrina', Annals of the American Academy, Volume 604, pp. 208-227.

Madrid, P.A., Grant, R., Reilly, M.J. and Redlener, N.B. (2006), 'Challenges in Meeting Immediate Emotional Needs: ShortTerm Impact of a Major Disaster on Children's Mental Health: Building Resiliency in the Aftermath of Hurricane Katrina', Pediatrics, Volume 117, pp. S448-S453.

Mills, J.W., Curtis, A., Pine, J., Kennedy, B., Jones, F., Ramani, R. and Bausch, D. (forthcoming), The Clearinghouse Concept: A Model for Geospatial Data Centralization and Dissemination in a Disaster', Disasters.

Morrow, B.H. (1999), 'Identifying and Mapping Community Vulnerability', Disasters, Volume 23, pp. 1-18.

Newsome, D.E. and Mitrani, J.E. (1993), 'Geographic Information System Applications in Emergency Management', Journal of Contingencies and Crisis Management, Volume 1, pp. 199-202.

ODOT (2007), Oregon Department of Transportation's Digital Video Log (DVL). https://keiko.odot.state.or.us/ whalecome324431c3ee61b8fa2602f107a5be6eff7c305ad0ff $\mathrm{fb} 1654 \mathrm{e} /$ whalecom0/cf/dvl/index.cfm (accessed 21 June 2007).

Pine, J.C. (1997), 'Geographic Information Systems (GIS) in Small Communities: Application of GIS in Emergency Management, Quick Response Research Report 99, Natural Hazards Center, University of Colorado. http://www.color ado.edu/hazards/research/qr/qr99.html (accessed: 25 June 2007).

Rehner, T.A., Kolbo, J.R., Trump, R., Smith, C. and Reid, D. (2000), 'Depression among Victims of South Mississippi's Methyl Parathion Disaster', National Association of Social Workers, Volume 25, pp. 33-40.

Thomas, D.S.K., Cutter, S.L., Hodgson, M., Gutekunst, M. and Jones, S. (2002), 'Use of Spatial Data and Geographic Technologies in Response to the September 11 Terrorist Attack, Quick Response Research Report 153, Natural Hazards Center, University of Colorado. http://www.color ado.edu/hazards/research/qr/qr153/qr153.html (accessed: 25 June 2007).

Waugh, W.L. Jr. (2006), 'The Political Costs of Failure in the Katrina and Rita Disasters', Annals of the American Academy, Volume 604, Pp. 10-25.

Yamazaki, F. (2001), 'Application of GIS and Remote Sensing for Disaster Assessment', Urban Safety Engineering, Volume 69, pp. 69-84. 